\title{
Transforming food and agriculture systems with agroecology
}

\author{
Stephen R. Gliessman ${ }^{1}$
}

Accepted: 21 April 2020 / Published online: 11 May 2020

(c) Springer Nature B.V. 2020

As an agroecologist, I am keenly aware of the vulnerabilities resulting from modern industrial food and agriculture systems, including: large areas planted to single genetically similar crops, animals raised in crowded confinement, heavy use of chemicals, consolidation of food and farming systems under corporate control, loss of small- and medium-scale farms, horrible conditions and pay for work in the fields and factories, an increase in health problems related to poor diet, and policies that support large-scale operations. Agroecologists say that our modern food systems, from the farm to the consumer, are broken.

I never expected, however, we would confront these vulnerabilities all at once as is happening as a result of the COVID-19 crisis: panic buying, breakdown of supply chains, farm and food workers at greater risk, more hunger and malnutrition, and other problems due to the simultaneous breakdown of so many parts of the food system, from production to distribution to consumption.

The system level approach of agroecology is a way to bring deep change - transformative change - to all parts of our agricultural and food systems. I define agroecology as the use of ecology-the science of how nature works-to design and manage sustainable food systems. Agroecology is transdisciplinary, participatory, action-oriented, and integrates social and environmental components. Agroecology offers an integrated set of solutions with transformational potential that reconciles three central challenges that agriculture faces today: feeding a growing population, conserving natural resources, and providing sustainable lives and livelihoods for farmers, for food system and farm workers, and for people who consume their products. Agroecology around the world has in common the following elements:

This article is part of the Topical Collection: Agriculture, Food \& Covid-19.

Stephen R. Gliessman

gliess@ucsc.edu

1 University of California, Santa Cruz, CA, USA
- Agroecology has three facets; it is equally a science, a praxis, and a social movement.

- Agroecology applies holistic ecological concepts, principles and knowledge to agricultural production, harnessing ecosystem functions to the maximum possible extent, maximizing functional biodiversity and strengthening biological regulation in agroecosystems rather than relying on external inputs.

- It is based on bottom-up and regional processes, helping to deliver contextualized solutions to local problems.

- Agroecological innovations are based on the co-creation of knowledge, combining science with the traditional, practical and local knowledge of producers. By enhancing their autonomy and adaptive capacity, agroecology empowers producers and communities as key agents of change.

- It includes an explicit focus on social and economic dimensions of food systems. Agroecology places a strong focus on food sovereignty, and especially the rights of women, youth and indigenous peoples.

- Using a political economy approach, it challenges the social and economic powers that lock in the industrial food and agriculture model.

- Agroecology is the ecology of the entire food system, from the field to the table, and everything in between.

The COVID-19 crisis is forcing us to look at short-term solutions, and gives us the opportunity to push forward with long-term transformational change. The change process begins with rebuilding resilience and reintroducing diversification, re-localizing food production and distribution, reducing input and import dependency, prioritizing food justice, equity and fairness, as we link all parts of the food system. This means reconnecting producers and consumers through short supply chain initiatives such as CSAs, farmers' markets and public procurement programs. Local food chains are not only resilient in the face of crises and trade restrictions, but also to get fresh food to people.

Great progress has been made over the past decade in developing, implementing, and documenting the benefits 
of agroecology. Agroecology's foundation as a system approach to transform the whole food system, and to reconcile economic, environmental, and social dimensions of sustainability is being recognized. Examples of agroecological transition are accumulating, tools for assessing agroecological advances developed, and food policy councils putting forward the needed steps towards transformation. We are seeing the emergence of a convergence around agroecology, with multiple stakeholders joining forces for food system change.

As we address the food vulnerabilities manifest by COVID-19 on the short-term, and as many people develop awareness of the importance of local food access, we also need to further the social and political movement for policy change on the long-term. Agroecology, in order to build resilience, pays attention to how food is produced as well as where it is produced, and by and for whom. Considering food as a basic human right rather than just a commodity for profit, we must further the difficult process of a paradigm shift to how we institute policy changes that promote sustainability for all parts of the food systems. In the US, the Farm Bill must become a Food and Farm Bill. We can't just wait for the next crisis. It is time to bring "culture" back to agri-culture and maintain support for localized food systems on a global level.

Publisher's Note Springer Nature remains neutral with regard to jurisdictional claims in published maps and institutional affiliations.

Stephen (Steve) R. Gliessman is Professor Emeritus of Agroecology at University of California Santa Cruz, where he held the Heller Endowed Chair of Agroecology for over 30 years. His research covers the broad area of the application of ecological concepts and principles to the design, management, and transition to sustainable food systems. $\mathrm{He}$ has a BA, MS, and PhD from UC Santa Barbara, has been a Kellogg Foundation Leadership Fellow and a Fulbright Fellow. He is Editor of Agroecology and Sustainable Food Systems, and his textbook of Agroecology is in its third edition and has been translated into multiple languages. 